\title{
The effects of holistic health group interventions on improving the cognitive ability of persons with mild cognitive impairment: a randomized controlled trial
}

\author{
This article was published in the following Dove Press journal: \\ Clinical Interventions in Aging \\ 25 September 2017 \\ Number of times this article has been viewed
}

\section{Kim-wan Young' \\ Petrus $\mathrm{Ng}^{\prime}$ \\ Timothy Kwok ${ }^{2}$ \\ Daphne Cheng'}

'Department of Social Work, Hong Kong Baptist University, Kowloon

Tong, ${ }^{2}$ Department of Medicine (Geriatric Division), Chinese

University of Hong Kong, Hong Kong
Correspondence: Kim-wan Young AABI025, Department of Social Work, Hong Kong Baptist University, Kowloon Tong, Hong Kong

Tel +85234116416

Fax +852 34II 7I 45

Email danielyoung@hkbu.edu.hk
Purpose: Persons with mild cognitive impairment (PwMCI) are at a higher risk of developing dementia than those without cognitive impairment. This research study aims to evaluate the effectiveness of a holistic health group intervention, which is based on the holistic brain health approach as well as an Eastern approach to health care, on improving the cognitive ability of Chinese PwMCI.

Research methods: In a randomized controlled trial (RCT), 38 Chinese PwMCI were randomly assigned to either a 10 -session holistic health intervention group or the control group. The holistic health treatment group attempted to promote the acceptance of their illness, enhance memory and coping skills, develop a positive lifestyle, maintain positive emotions, and facilitate emotional support among participants. The 10-session holistic health group intervention was structured, with each session conducted once per week and 90 minutes in length. Control group patients and their family caregivers received standardized basic educational materials that provided basic information on cognitive decline for them to read at home. The Montreal Cognitive Assessment (MoCA) test was used to assess the cognitive ability of PwMCI in the pre- and posttreatment periods by a research assistant who was blind to the group assignment of the participants.

Results: The paired-samples $t$-test indicated that the treatment group $(n=18)$ showed significant improvement in the MoCA score, whereas the control group $(n=20)$ did not. Moreover, $2 \times 2$ (group $\times$ time) repeated-measures analysis of covariance (ANCOVA) demonstrated that the holistic health group treatment was significantly more effective than the control intervention in improving the MoCA score, with a moderate effect size, and improving the delayed recall (ie, short-term memory), with a strong effect size, after controlling for age, sex, education, and marital status.

Conclusion: This present RCT provides evidence to support the feasibility and effectiveness of the holistic health group intervention in improving the cognitive and short-term memory abilities of PwMCI.

Keywords: mild cognitive impairment, cognitive training, cognitive ability, short-term memory, Montreal Cognitive Assessment, holistic health group

\section{Introduction}

Mild cognitive impairment (MCI) is an intermediate stage of cognitive function between normal cognitive aging and dementia. ${ }^{1}$ Specifically, persons with MCI (PwMCI) are those who have subjective cognitive complaints, show cognitive impairment in one or 
more domains, preserve functional independence, and present no dementia. ${ }^{2}$ The prevalence rate of MCI ranges from $10 \%$ to $20 \%$ for people aged 65 years or more. ${ }^{1,3}$ PwMCI are at risk of the development of dementia at a rate of $5 \%-10 \%$, which is higher than that of healthy older people without MCI. ${ }^{1,4}$ Thus, there is an urgent need to develop effective interventions to improve the cognitive ability of PwMCI to delay their progression to dementia.

At present, the effectiveness of pharmacological treatment for MCI remains uncertain. ${ }^{2,3,5}$ Furthermore, several reviews of research evidence have suggested that nonpharmacological interventions can improve the cognitive ability of PwMCI., ${ }^{4-9}$ In particular, cognitive training, ${ }^{7}$ physical exercise, ${ }^{1,10,11}$ and social activities ${ }^{12,13}$ have been shown to be effective in improving the cognitive ability of PwMCI.

Recently, multicomponent intervention, which combines various kinds of nonpharmacological interventions, such as cognitive training, physical exercise, relation skills, and social group activities, into one single intervention has been developed and shown to be effective in improving the cognitive ability of PwMCI. ${ }^{11,14-20}$ Additionally, after completing treatment with the multicomponent intervention, improvements in cognitive ability can be maintained up to 2 years. ${ }^{21}$

However, generalizations of these positive research results on multicomponent intervention have been limited due to various factors. First, there is great variety within multicomponent interventions. For example, different multicomponent interventions may have different intervention durations, ranging from 6 weeks to 7 weeks ${ }^{17,18}$ up to 9 months. ${ }^{15}$ Second, different multicomponent interventions have different theoretical approaches with a different emphasis in their program elements. Some multicomponent interventions focus more on developing memory skills, ${ }^{15,16,18,19}$ whereas others promote healthy lifestyles for brain health. ${ }^{17,19}$ Third, the provision of multicomponent intervention should be culturally sensitive when it is applied to Chinese PwMCI. Differences in linguistic property, cultural, and educational levels may affect the effects of training. ${ }^{22}$ For example, Chinese PwMCI may not understand the mnemonic strategies originally designed for Western patients. Additionally, Chinese PwMCI prefer to practice tai chi to aerobics. Thus, it is important to indigenize the content of PwMCI multicomponent interventions in order to make them suitable for the local culture and context. Fourth, due to cultural influences, Chinese persons with neurocognitive disorder have somewhat different concerns about their cognitive decline. ${ }^{23}$ Under traditional Chinese values, especially Confucianism, persons with neurocognitive disorder are perceived as those who are not competent members of society, those who fail to comply with the five cardinal relations, and those who cause "loss of face" and "shame" within the family and social systems..$^{24,25}$ Thus, as shown in a local survey, Chinese persons with neurocognitive disorder express the fear of being labeled as mentally ill and losing their status within the family, in addition to feeling guilty for being dependent, being a burden to their family, and feeling helplessness. ${ }^{23}$ Therefore, it is important for advocates of multicomponent intervention to address these special concerns of Chinese individuals with neurocognitive disorder.

\section{Eastern holistic health approach}

A multicomponent holistic health group intervention, which is founded on an Eastern approach to health care, ${ }^{26,27}$ has recently been developed to meet the special needs of Chinese people with neurocognitive disorders, ${ }^{28}$ with the following characteristics. First, this approach emphasizes holistic care needs (ie, the biopsychosocial-spiritual health of individuals) rather than only targeting the cognitive decline. Additionally, the biological/physical, psychological, social, and spiritual aspects of individuals are considered to be interactive, and thus strategies that promote physical health will enhance brain health and cognitive ability. Second, according to the YinYang philosophy, strengths and weaknesses coexist within individuals even when they are suffering from a chronic illness, ${ }^{29}$ and therefore, this approach helps individuals to recognize their own strengths and mobilize support systems in facing with cognitive impairment. Third, this approach enhances individual coping skills and memory skills in order to combat cognitive decline. Fourth, this approach facilitates the development of a healthy lifestyle, such as adhering to a proper diet, physical exercise and recreational activities, maintaining a positive mood, and appreciating the family caregiver. Finally, this approach promotes the acceptance and tolerance of life adversities brought upon by their illness. Previous research results supported the efficacy of this group intervention for people with neurocognitive disorder and found that it significantly reduced depressive mood and improved the health-related quality of life of participants with neurocognitive disorder. ${ }^{25,28}$

This present study is an extension of a previous study. ${ }^{28}$ This present study adds to the previous work by 1) modifying the contents of the holistic health group intervention to suit the needs of PwMCI and 2) evaluating the effectiveness of this holistic health group intervention in improving the cognitive ability of Chinese PwMCI. In the present study, 
in order to adapt the holistic health group intervention for PwMCI in a local context, the holistic health group intervention attempts to promote the acceptance of illness, enhance memory and coping skills, develop a positive lifestyle, maintain positive emotions, recognize individual strengths, improve communication skills with family caregivers, and facilitate emotional support among participants. Additionally, this holistic health group intervention helps participants to develop cognitive strategies, including internal and external strategies. ${ }^{30}$ External strategies include modifying the living environment, as well as using aids such as calendars, checklists, and reminders. Internal strategies include attention, categorization, association, visual imagery, and mnemonics. It is hypothesized that this holistic health group intervention is effective in improving the cognitive ability of Chinese PwMCI.

\section{Research methods}

By adopting a randomized controlled trial (RCT) approach, 38 Chinese PwMCI were randomly assigned to either a treatment group or the control group. These participants were living at home and were recruited from centers for the elderly operated by nongovernmental organizations. The group assignment process was performed by DK Young, who was not involved in any data collection process. A research assistant who was blind to the group assignment of the participants used standardized assessment tools to collect the study data of all participants within 4 weeks before treatment and within 4 weeks after completing treatment. All participants received HK\$100 as an incentive payment after completing all assessments.

\section{Ethical considerations}

The ethical aspects of this study were evaluated and approved by the Research Committee of the Hong Kong Baptist University (reference number: FRG1/14-15/050). Written informed consent was obtained from all participants with $\mathrm{MCI}$, as well as their family caregivers, on the day of pretreatment assessment.

\section{Treatment and control groups}

The holistic health group intervention was structured and consisted of 10 sessions. Each session was conducted once per week and was, on average, 90 minutes in length. The group size was 8-10 PwMCI. Family caregivers of the treatment group patients were encouraged to participate in two sessions focusing on caring and communication skills. Each group was led by a social worker who had more than
Table I Session outline of 10-week holistic health group intervention for persons with mild cognitive impairment

\begin{tabular}{|c|c|}
\hline Session & Discussion topic \\
\hline I & $\begin{array}{l}\text { Promoting mutual trust and group confidentiality among } \\
\text { participants }\end{array}$ \\
\hline 2 & $\begin{array}{l}\text { Understanding cognitive impairment } \\
\text { Sharing the difficulties of having cognitive decline }\end{array}$ \\
\hline 3 & $\begin{array}{l}\text { Learning strategies to enhance their memory and learning: } \\
\text { I) attention, categorization, and organization }\end{array}$ \\
\hline 4 & $\begin{array}{l}\text { Learning strategies to enhance their memory and learning: } \\
\text { 2) mnemonics and visual imagery }\end{array}$ \\
\hline 5 & Developing positive life style: I) physical exercise \\
\hline 6 & Developing positive life style: 2) maintaining positive mood \\
\hline 7 & $\begin{array}{l}\text { Developing positive life style: } 3 \text { ) recognizing own strengths } \\
\text { even with having cognitive decline }\end{array}$ \\
\hline 8 & $\begin{array}{l}\text { Communication skill between participants and family } \\
\text { caregivers }\end{array}$ \\
\hline 9 & $\begin{array}{l}\text { Positive and harmonious relationship between participants } \\
\text { and family caregivers }\end{array}$ \\
\hline 10 & $\begin{array}{l}\text { Planning for future and referring to sources of } \\
\text { ongoing support }\end{array}$ \\
\hline
\end{tabular}

2 years of working experience with neurocognitive disorders. A standardized manual was produced by the author for use in the group intervention. Table 1 provides an outline of the contents of the holistic health group interventions. The social worker received training on the standardized manual by DK Young. Additionally, the author attended some group sessions, acting as observer without changing any group intervention contents, and provided regular supervision to the social worker to ensure that the standardized manual was properly and fully implemented. Moreover, the social worker used group work skills to facilitate sharing and mutual support among group participants.

The control group participants with MCI, as well as their family caregivers, received three pages of written educational material providing basic information on neurocognitive disorders, which they were encouraged to read at home. This information was summarized from an educational leaflet on neurocognitive disorder produced by the public health care unit. Control group participants and their family caregivers were not required to attend any group sessions and were contacted only during the pre- and posttreatment periods for assessment purposes.

\section{Subject inclusion criteria}

In this study, the inclusion criteria were as follows 1) age of 60 years or more; 2) a diagnosis of MCI or mild neurocognitive disorder according to the criteria of the Diagnostic and Statistical Manual of Mental Disorders (Fifth Edition); ${ }^{31}$ 3 ) an awareness of memory loss and a history of memory 
complaints; and 4) the ability to participate independently in a group setting. Participants who did not have a diagnosis of MCI or mild neurocognitive disorder were assessed by the researcher by using a screening tool (ie, the Montreal Cognitive Assessment [MoCA] $).{ }^{32}$ The cognitive ability of participants was also assessed by the Mini Mental State Examination (MMSE) (Chinese version), which has been found to have satisfactory validity, internal consistency $(\alpha=0.80-0.95)$, and test-retest reliability $(r=0.72){ }^{33}$

\section{Outcome assessment tools}

The MoCA tool (Chinese version), ${ }^{32}$ which has been validated and widely used internationally, was used for outcome assessment. ${ }^{1,34}$ The MoCA assesses various cognitive domains, including attention and concentration, executive functions, memory, language, visuoconstructional skills, conceptual thinking, calculations, and orientation. The reliability and validity of the Chinese version of MoCA have been tested to be satisfactory (Cronbach's $\alpha=0.77$ ). ${ }^{32}$ The score is summed over the items. The whole scale has a maximum score of 30, with higher scores indicating better cognitive ability. According to the original scale, ${ }^{34}$ a MoCA cutoff point $<26$ and $>17$ is indicative of MCI, which has been adopted in this study.

\section{Data analyses}

The analysis was carried out according to an intention-to-treat principle, using last observation carried forward (LOCF) analysis for missing data. The baseline demographic and clinical characteristics of the treatment and control groups were compared by using chi-square $\left(\chi^{2}\right)$ tests for the categorical variables and independent samples $t$-test for continuous variables. A paired-samples $t$-test was used to analyze the significant changes in the pre- and posttreatment MoCA scores for both the treatment and the control groups. To investigate the magnitude of the treatment effect, the outcome measure was analyzed using the general linear model $2 \times 2$ repeated-measures analysis of covariance (ANCOVA), with the two groups (treatment and control groups) as betweensubject factors and the two outcome assessments (pre- and posttreatment scores) as within-subject factors, adjusting for age, sex, education, and marital status. The effect sizes were calculated using the partial eta-square. For the partial eta-square, the values $0.01,0.06$, and 0.14 were considered small, moderate, and large effects, respectively. ${ }^{35}$ For all analyses, two-tailed $P$-values $<0.05$ indicate statistical significance. Data analyses were performed using SPSS 22.0 (IBM Corporation, Armonk, NY, USA).

\section{Results}

A total of 50 participants with MCI were recruited from the centers for the elderly. However, 12 did not meet the inclusion criteria and were hence excluded. The remaining 38 subjects were randomly assigned to a treatment group or the control group. Of these, 18 were placed in the treatment group and 20 were assigned to the control group. Two treatment groups and two control groups were formed. Each treatment group consisted of $\sim 8-10$ participants with MCI. Figure 1 illustrates the recruitment procedure. After the study was completed, 32 treatment group subjects finished all of the assessments. Two dropped out from the treatment group and four dropped out from the control group.

\section{Characteristics of the research sample}

Table 2 provides the baseline demographic data and measures of all the participants with MCI $(n=38)$. The mean age of the participants was $75.0(\mathrm{SD}=6.0)$ years. The majority $(86.8 \%, n=33)$ were female, had received a primary school or higher education $(78.9 \%, \mathrm{n}=30)$, and lived with their family members $(65.8 \%, n=25)$. A little more than half $(52.6 \%$, $\mathrm{n}=20$ ) were married, followed by widowed, divorced, or separated participants $(44.7 \%, \mathrm{n}=17)$. None of them received a diagnosis of MCI from their medical officers, and all of them were as assessed as having MCI as per the MoCA by the researcher. Two-thirds $(63.2 \%, n=24)$ suffered from one or more physical illnesses, and they reported no change in medication during the pre- and posttreatment period.

\section{Baseline assessment score}

The independent $t$-test and chi-square analyses showed no significant difference between the treatment and control groups in terms of all baseline demographic variables, including the MoCA and MMSE scores (Table 2 shows the data analysis). Additionally, those participants who dropped out did not show any significant difference in any of their baseline demographic and clinical variables compared with the retained participants. Among all participants, a mean MoCA score of 21.5 (SD =2.2) and mean MMSE score of $24.8(\mathrm{SD}=1.6)$ were observed.

\section{Treatment outcomes}

Table 3 summarizes the change in the MoCA score for both the treatment and the control groups. The results of a pairedsamples $t$-test demonstrate that after completing the group intervention, the treatment group showed significant improvement in the MoCA score from 21.00 ( $\mathrm{SD}=2.81$ ) to 23.56 $(\mathrm{SD}=2.90)(t=4.25, P<0.01)$. Additionally, the treatment 


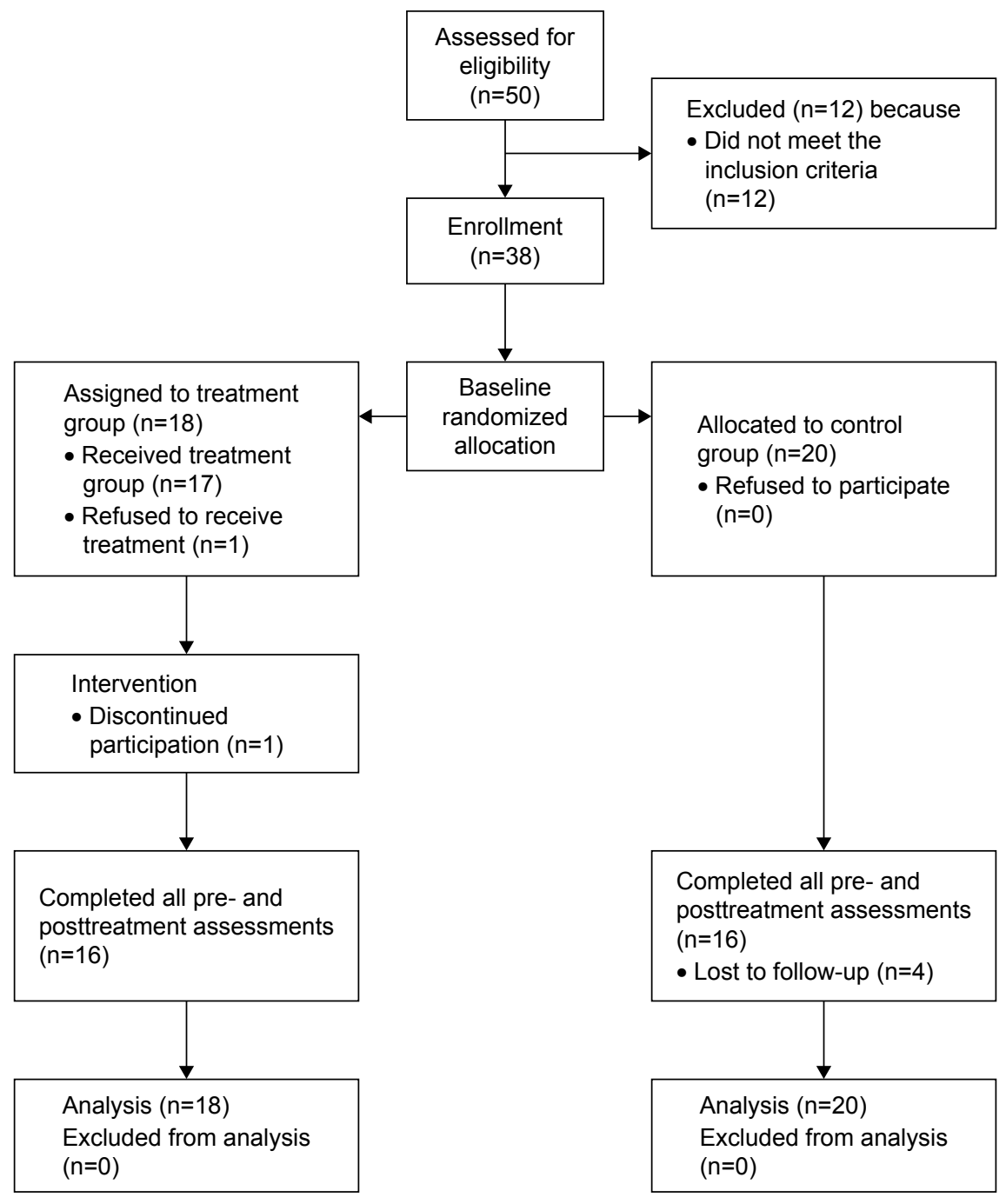

Figure I Flow of participants through each stage of the study.

group showed significant improvement in the adjusted MoCA score from $21.61(\mathrm{SD}=2.50)$ to $24.17(\mathrm{SD}=2.88)(t=4.25$, $P<0.01)$, alternative trail making score from $0.56(\mathrm{SD}=0.51)$ to 0.83 ( $\mathrm{SD}=0.38)(t=2.56, P<0.05)$, naming score from $2.39(\mathrm{SD}=0.78)$ to $2.61(\mathrm{SD}=0.50)(t=2.20, P<0.05)$, and delayed recall score from $1.00(\mathrm{SD}=1.41)$ to $2.11(\mathrm{SD}=1.57)$ $(t=2.56, P<0.05)$.

The 2 (group) $\times 2$ (time) repeated-measures ANCOVA demonstrates that the holistic health treatment was significantly more effective than the control intervention in improving the MoCA score, controlling for age, sex, education, and marital status ( $F=4.45, P<0.05)$, with a moderate-to-strong effect size (partial eta-square $=0.13$ ). Additionally, the holistic health intervention was significantly more effective than the control intervention at improving the adjusted MoCA score $(F=4.28, P<0.05)$, with a moderate-to-strong effect size (partial eta-square $=0.12$ ), and improving the delayed recall score $(F=5.04, P<0.05)$, with a strong effect size (partial eta-square $=0.14$ ), after controlling for age, sex, education, and marital status (Figures 2 and 3).

\section{Discussion}

This present study shows that the multicomponent holistic health group intervention significantly improves the cognitive ability of participants with MCI, supporting the feasibility and effectiveness of the multicomponent intervention in the local context. In particular, ANCOVA and paired-samples $t$-test demonstrate that the holistic health group intervention was more effective than the control intervention at improving the overall cognitive ability and delayed recall (ie, short-term memory) of PwMCI even after controlling for the differences between holistic health group treatment and control groups in terms of various demographic variables such as age, sex, educational level, and marital status. 
Table 2 Baseline characteristics of all participants with mild cognitive impairment

\begin{tabular}{|c|c|c|c|c|c|c|}
\hline \multirow[t]{2}{*}{ Characteristics } & \multirow[t]{2}{*}{$\begin{array}{l}\text { Valid } \\
\text { data }\end{array}$} & \multirow{2}{*}{$\begin{array}{l}\text { Treatment group } \\
(\mathrm{n}=18)\end{array}$} & \multirow{2}{*}{$\begin{array}{l}\begin{array}{l}\text { Control group } \\
(\mathrm{n}=20)\end{array} \\
\mathrm{n}(\%)\end{array}$} & \multirow{2}{*}{$\begin{array}{l}\begin{array}{l}\text { Total } \\
(n=38)\end{array} \\
n(\%)\end{array}$} & \multirow[t]{2}{*}{$\chi^{2}$} & \multirow[t]{2}{*}{$P$-value } \\
\hline & & & & & & \\
\hline Sex & 38 & - & - & - & 2.459 & $0.117 \mathrm{~ns}$ \\
\hline Male & - & $4(10.53)$ & $\mathrm{I}(2.63)$ & $5(13.16)$ & - & - \\
\hline Female & - & $14(36.84)$ & $19(50.00)$ & $33(86.84)$ & & - \\
\hline Marital status $^{a}$ & 38 & - & - & - & 2.351 & $0.503 \mathrm{~ns}$ \\
\hline Single & - & $0(0.00)$ & $\mathrm{I}(2.63)$ & I (2.63) & - & - \\
\hline Married & - & $9(23.68)$ & II (28.95) & $20(52.63)$ & & - \\
\hline Widowed, divorced, or separated & - & $9(23.68)$ & $8(21.05)$ & $17(44.74)$ & & - \\
\hline Educational level $^{2}$ & 38 & - & - & - & 0.028 & $0.986 \mathrm{~ns}$ \\
\hline None & - & $4(10.53)$ & $4(10.53)$ & $8(21.06)$ & - & - \\
\hline Primary & - & $7(18.42)$ & $8(21.06)$ & $15(39.47)$ & & - \\
\hline Secondary & - & $7(18.42)$ & $8(21.06)$ & $15(39.47)$ & & - \\
\hline College & - & $0(0.00)$ & $0(0.00)$ & $0(0.00)$ & & - \\
\hline Living with ${ }^{\mathrm{a}}$ & 38 & - & - & - & 6.899 & $0.141 \mathrm{~ns}$ \\
\hline Alone & - & $6(15.78)$ & $6(15.78)$ & $12(31.58)$ & - & - \\
\hline Family members & - & $12(3 \mid .58)$ & $13(34.21)$ & $25(65.79)$ & & - \\
\hline Family members and domestic helper & - & $0(0.00)$ & $\mathrm{I}(2.63)$ & $\mathrm{I}(2.63)$ & & - \\
\hline Domestic helper only & - & $0(0.00)$ & $0(0.00)$ & $0(0.00)$ & & - \\
\hline Variables & $\mathbf{n}$ & $M(S D)$ & $M(S D)$ & $M(S D)$ & $t(P)$ & $\begin{array}{l}95 \% \mathrm{Cl} \text { of the } \\
\text { difference }\end{array}$ \\
\hline$A_{g} e^{b}$ & 38 & $75.50(6.45)$ & $74.50(5.7 \mathrm{I})$ & $74.97(6.01)$ & $0.507(0.615)$ & $-2.998,4.998$ \\
\hline Number of physical illnesses ${ }^{b}$ & 38 & $0.83(0.92)$ & $0.85(0.8 \mathrm{I})$ & $0.84(0.86)$ & $-0.059(0.953)$ & $-0.588,0.554$ \\
\hline MoCA score ${ }^{b}$ & 38 & $21.61(2.50)$ & $21.40(1.88)$ & $21.50(2.17)$ & $0.296(0.769)$ & $-1.234,1.656$ \\
\hline MMSE score ${ }^{b}$ & 38 & $25.11(1.49)$ & $24.45(1.67)$ & $24.76(1.60)$ & $1.282(0.208)$ & $-0.385,1.707$ \\
\hline
\end{tabular}

Notes: aPearson's chi-square; 'Independent samples $t$-test; $M$, mean.

Abbreviations: MoCA, Montreal Cognitive Assessment (Hong Kong version); MMSE, Mini Mental State Examination (Chinese version); ns, nonsignificant.

Table 3 Pretest, posttest, and comparison of score change between the intervention and control groups on assessment

\begin{tabular}{|c|c|c|c|c|c|c|}
\hline \multirow[t]{2}{*}{ Variables } & $\begin{array}{l}\text { Treatment group } \\
(\mathrm{n}=18)\end{array}$ & \multirow[t]{2}{*}{$t(P)$} & $\begin{array}{l}\text { Control group } \\
(n=20)\end{array}$ & \multirow[t]{2}{*}{$t(P)$} & \multirow[t]{2}{*}{$F(P)$} & \multirow[t]{2}{*}{$\begin{array}{l}\text { Partial eta- } \\
\text { squared }\end{array}$} \\
\hline & Mean (SD) & & Mean (SD) & & & \\
\hline MoCA score & & $4.254(0.001)^{* *}$ & & $0.000(1.000)$ & $4.452(0.043)^{*}$ & 0.126 \\
\hline Pretest & $21.00(2.8 I)$ & & $20.08(1.96)$ & & & \\
\hline Posttest & $23.56(2.90)$ & & $20.08(2.65)$ & & & \\
\hline Score change & $2.56(2.55)$ & & $-0.00(2.10)$ & & & \\
\hline $95 \% \mathrm{Cl}$ of the score change & $1.29,3.28$ & & $-0.98,0.98$ & & & \\
\hline MoCA (adj) score & & $4.254(0.001)^{* *}$ & & $0.000(1.000)$ & $4.282(0.047)^{*}$ & 0.121 \\
\hline Pretest & $2 \mathrm{I} .6 \mathrm{I}(2.50)$ & & $21.40(1.88)$ & & & \\
\hline Posttest & $24.17(2.88)$ & & $21.40(2.68)$ & & & \\
\hline Score change & $2.56(2.55)$ & & $0.000(2.10)$ & & & \\
\hline $95 \% \mathrm{Cl}$ of the score change & $1.29,3.82$ & & $-0.98,0.98$ & & & \\
\hline Alternative trail making & & $2.557(0.020)^{*}$ & & $-1.000(0.330)$ & $0.485(0.491)$ & 0.015 \\
\hline Pretest & $0.56(0.5 \mathrm{I})$ & & $0.65(0.49)$ & & & \\
\hline Posttest & $0.83(0.38)$ & & $0.50(0.5 \mathrm{I})$ & & & \\
\hline Score change & $0.28(0.46)$ & & $-0.15(0.67)$ & & & \\
\hline $95 \% \mathrm{Cl}$ of the score change & $0.05,0.51$ & & $-0.46,0.16$ & & & \\
\hline Cube drawing test & & $0.566(0.579)$ & & $-1.710(0.104)$ & $0.410(0.527)$ & 0.013 \\
\hline Pretest & $0.33(0.49)$ & & $0.25(0.44)$ & & & \\
\hline Posttest & $0.39(0.50)$ & & $0.45(0.5 \mathrm{I})$ & & & \\
\hline Score change & $0.06(0.42)$ & & $0.20(0.52)$ & & & \\
\hline $95 \% \mathrm{Cl}$ of the score change & $-0.15,0.26$ & & $-0.05,0.45$ & & & \\
\hline
\end{tabular}


Table 3 (Continued)

\begin{tabular}{|c|c|c|c|c|c|c|}
\hline \multirow[t]{2}{*}{ Variables } & $\begin{array}{l}\text { Treatment group } \\
(\mathrm{n}=18)\end{array}$ & \multirow[t]{2}{*}{$t(P)$} & \multirow{2}{*}{$\begin{array}{l}\text { Control group } \\
(n=20) \\
\text { Mean (SD) }\end{array}$} & \multirow[t]{2}{*}{$t(P)$} & \multirow[t]{2}{*}{$F(P)$} & \multirow[t]{2}{*}{$\begin{array}{l}\text { Partial eta- } \\
\text { squared }\end{array}$} \\
\hline & Mean (SD) & & & & & \\
\hline Clock drawing test & & $\mathrm{I} .844(0.083)$ & & $0.825(0.419)$ & $0.476(0.496)$ & 0.015 \\
\hline Pretest & $2.6 \mathrm{I}(0.78)$ & & $2.45(0.83)$ & & & \\
\hline Posttest & $2.78(0.55)$ & & $2.60(0.60)$ & & & \\
\hline Score change & $0.17(0.38)$ & & $0.15(0.8 \mathrm{I})$ & & & \\
\hline $95 \% \mathrm{Cl}$ of the score change & $-0.02,0.36$ & & $-0.23,0.53$ & & & \\
\hline Naming & & $2.204(0.042)^{*}$ & & $0.634(0.54 I)$ & $\mathrm{I} .654(0.208)$ & 0.051 \\
\hline Pretest & $2.39(0.78)$ & & $2.05(0.6 I)$ & & & \\
\hline Posttest & $2.61(0.50)$ & & $2.15(0.68)$ & & & \\
\hline Score change & $0.22(0.43)$ & & $0.10(0.72)$ & & & \\
\hline $95 \% \mathrm{Cl}$ of the score change & $0.01,0.44$ & & $-0.24,0.44$ & & & \\
\hline Attention & & $1.458(0.163)$ & & $0.418(0.68 I)$ & $1.090(0.304)$ & 0.034 \\
\hline Pretest & $4.72(0.90)$ & & $4.85(1.18)$ & & & \\
\hline Posttest & $5.06(1.06)$ & & $4.75(0.97)$ & & & \\
\hline Score change & $0.33(0.97)$ & & $-0.10(0.97)$ & & & \\
\hline $95 \% \mathrm{Cl}$ of the score change & $-0.15,0.82$ & & $-0.60,0.40$ & & & \\
\hline Sentence repetition & & NA & & NA & NA & NA \\
\hline Pretest & $2.00(0.00)$ & & $2.00(0.00)$ & & & \\
\hline Posttest & $2.00(0.00)$ & & $2.00(0.00)$ & & & \\
\hline Score change & $0.00(0.00)$ & & $0.00(0.00)$ & & & \\
\hline $95 \% \mathrm{Cl}$ of the score change & $0.00(0.00)$ & & $0.00(0.00)$ & & & \\
\hline Verbal fluency & & $1.000(0.331)$ & & NA & $0.469(0.499)$ & 0.015 \\
\hline Pretest & $0.89(0.32)$ & & $0.95(0.22)$ & & & \\
\hline Posttest & $0.94(0.24)$ & & $0.95(0.22)$ & & & \\
\hline Score change & $0.06(0.24)$ & & $0.00(0.00)$ & & & \\
\hline $95 \% \mathrm{Cl}$ of the score change & $-0.06,0.17$ & & $0.00(0.00)$ & & & \\
\hline Abstraction & & $1.458(0.163)$ & & $0.438(0.666)$ & $0.608(0.442)$ & 0.019 \\
\hline Pretest & $1.28(0.58)$ & & $1.30(0.57)$ & & & \\
\hline Posttest & $\mathrm{I} .50(0.5 \mathrm{I})$ & & $1.35(0.59)$ & & & \\
\hline Score change & $0.22(0.65)$ & & $0.00(1.12)$ & & & \\
\hline $95 \% \mathrm{Cl}$ of the score change & $-10,0.54$ & & $-0.19,0.29$ & & & \\
\hline Delayed recall & & $2.557(0.020)^{*}$ & & $-0.000(1.000)$ & $5.04 \mathrm{I}(0.032)^{*}$ & 0.140 \\
\hline Pretest & $\mathrm{I} .00(\mathrm{I} .4 \mathrm{I})$ & & $0.80(0.89)$ & & & \\
\hline Posttest & $2.11(1.57)$ & & $0.80(1.06)$ & & & \\
\hline Score change & I.II (I.84) & & $-0.05(1.09)$ & & & \\
\hline $95 \% \mathrm{Cl}$ of the score change & $0.19,2.03$ & & $-0.53,53$ & & & \\
\hline Orientation & & $0.294(0.772)$ & & $-0.567(0.577)$ & $0.000(0.994)$ & 0.000 \\
\hline Pretest & $5.22(0.8 \mathrm{I})$ & & $5.50(0.6 I)$ & & & \\
\hline Posttest & $5.28(1.02)$ & & $5.35(1.09)$ & & & \\
\hline Score change & $0.06(0.80)$ & & $-0.15(1.18)$ & & & \\
\hline $95 \% \mathrm{Cl}$ of the score change & $-0.34,46$ & & $1.70,40$ & & & \\
\hline
\end{tabular}

Notes: *Significant at $P<0.05$; **significant at $P<0.01$; $t$ : paired-samples $t$-test; $F$ : ANCOVA controlling for age, sex, marital status, and education level.

Abbreviations: adj, adjusted; ANCOVA, analysis of covariance; MoCA, Montreal Cognitive Assessment (Hong Kong version); MoCA (adj), Montreal Cognitive Assessment (Hong Kong version) adjusted score; NA, not applicable.

Two theoretical approaches of multicomponent intervention have been developed in Western countries. The first approach focuses more on evidence-based cognitive interventions. ${ }^{15,16,18,20}$ There are three types of cognitive interventions: cognitive stimulation, cognitive training, and cognitive rehabilitation. ${ }^{36,37}$ Cognitive stimulation emphasizes the activities conducted in a group format to increase cognitive and social functioning in a nonspecific manner.
Cognitive training involves teaching strategies and skills to improve specific aspects of cognitive functioning. Cognitive rehabilitation entails individually tailored programs targeting specific activities of daily living. Research suggests that cognitive training, ${ }^{7,9}$ cognitive stimulation, ${ }^{38}$ and cognitive rehabilitation ${ }^{39}$ are effective in improving cognitive functioning for PwMCI. Accordingly, a number of specific training activities (eg, visual imagery, mnemonics, and so on) 


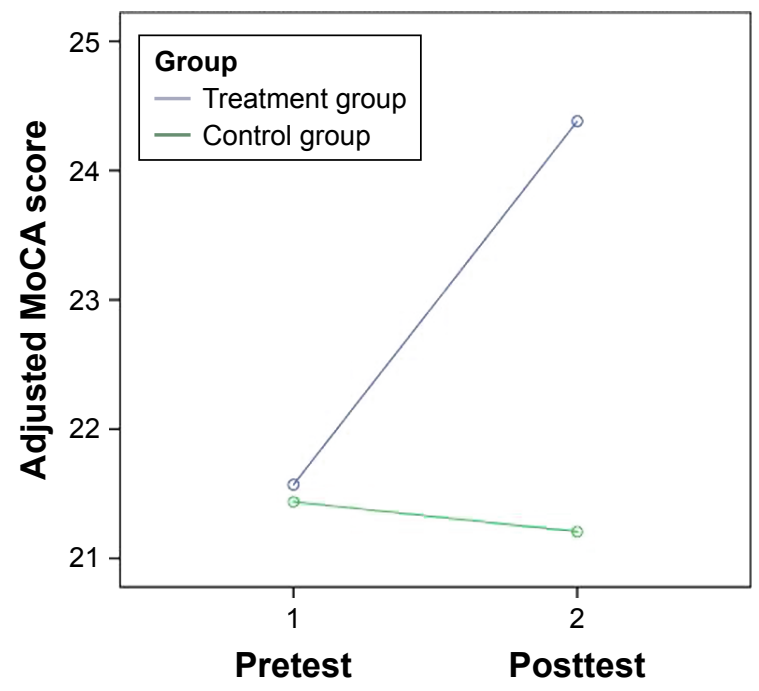

Figure 2 Change in adjusted MoCA score of the treatment and the control groups. Note: Covariates appearing in the model are evaluated at the following values: age $=74.97$, sex $=0.13$, education $=2.18$, marital status $=3.26$.

Abbreviation: MoCA, Montreal Cognitive Assessment (Hong Kong version).

have been developed ${ }^{14,16,40}$ and are included - in addition to physical exercise as well as social and recreational activities in multicomponent interventions. ${ }^{14,18,20}$ However, there are great variations among interventions based on this approach, including differences in duration, focus, and training activities. More research studies are needed to investigate the appropriate duration, focus, and training activities for PwMCI across cultures and societies.

A second approach, named the holistic brain health approach, has recently been developed. ${ }^{17,19}$ In this method, a holistic approach to brain health is employed with a

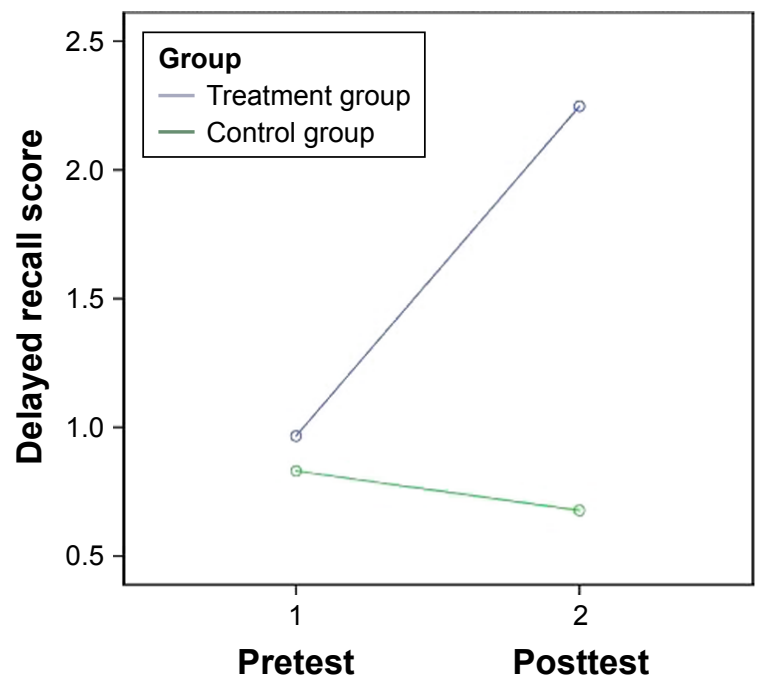

Figure 3 Change in delayed recall score of the treatment and the control groups. Note: Covariates appearing in the model are evaluated at the following values: age $=74.97$, sex $=0.13$, education $=2.18$, marital status $=3.26$. combination of diet, exercise, socialization, stress reduction, and mental stimulation and this method can delay the onset of neurocognitive disorder. ${ }^{17}$ Research supports the effectiveness of short-term structured interventions based on this holistic brain health approach in terms of improving the cognitive functioning of PwMCI. ${ }^{17,19}$ For example, a 10-session multicomponent intervention that emphasized establishing a healthy lifestyle through learning memory skills, stress reduction, recreation, nutrition, and community resources was found to enhance memory strategies in the daily life of PwMCI. ${ }^{19}$ However, because previous research studies did not report a change in the objective cognitive ability of research subjects after intervention, ${ }^{17,19}$ it remains unclear whether the holistic brain health approach is effective at improving the cognitive ability of PwMCI.

As discussed previously, due to cultural influence, Chinese individuals with neurocognitive disorder have somewhat different concerns about their cognitive decline..$^{23,25}$ Chinese persons with neurocognitive disorder express fear of being labeled as mentally ill and losing their status within the family, in addition to feeling guilty for being dependent, being a burden to their family, and feeling helplessness. ${ }^{23}$ Therefore, it is important for advocates of a multicomponent intervention to address these special concerns of Chinese PwMCI.

The holistic health group intervention, which is founded on the Eastern health care approach, is a unique application and adaptation of the holistic brain health approach in Chinese cultures and societies. This present study shows that the short-term structured holistic health group intervention, which aims to meet the special concerns of Chinese PwMCI, significantly improves the cognitive ability of participants with MCI, supporting the feasibility and effectiveness of the short-term structured multicomponent intervention for PwMCI in the local context. More important, the present RCT is one of the few studies demonstrating the effectiveness of the short-term structured holistic brain health intervention to improve the objective cognitive ability and short-term memory of PwMCI.

The identification of the essential group elements contributing to the effectiveness of this holistic health group intervention certainly needs further investigation. Some observations on the effective group elements of this holistic health group intervention are highlighted herein. First, it is feasible, appropriate, and useful for this holistic health group intervention to promote the acceptance of illness, develop a positive lifestyle, maintain positive emotions, recognize individual strengths, and improve communication and relationships with family caregivers among PwMCI. Second, it is also 
important for the holistic health group intervention to enhance various internal and external cognitive strategies for participants, ${ }^{30}$ such as attention, categorization, association, visual imagery, and mnemonics. Third, it is important for the holistic health group intervention to facilitate emotional support among the participants who share similar difficulties that are encountered in daily living. By receiving emotional support from others, participants can reduce their anxiety and helplessness, which are typical characteristics of MCI.

Several methodological limitations of this RCT require attention. First, the generalizability of the research results is limited by the small sample size. In the future, a larger-scale RCT should be conducted to further validate the effectiveness and benefits of the holistic health group model for PwMCI across cultures and societies. Second, the studied group was dominated by female participants, which may limit the generalization of research results to male participants. Third, this studied group lacked proper control in drug treatment between the treatment and the control groups, although all participants reported no change in medication during the pre- and posttreatment period. The change in cognitive functioning might be due to the change in medications, which might also limit generalization of the research result. Finally, in this study, promoting the acceptance of illness, enhancing learning and memory skills, developing a positive lifestyle, maintaining positive emotions, recognizing individual strengths, improving relationships with family caregivers, and facilitating emotional support among participants are thought to be essential elements of this holistic health group intervention. However, no standardized tools have been adopted to assess these elements in this study. Therefore, further research studies should be conducted to identify the essential elements of holistic health group interventions for PwMCI.

This present study shows that a holistic health group intervention significantly improves the cognitive and memory ability of participants with MCI, supporting the feasibility and effectiveness of holistic health group interventions.

\section{Acknowledgment}

This research work was financially supported by the Faculty of Social Sciences, Hong Kong Baptist University (FRG1/ 14-15/050).

\section{Disclosure}

The authors report no conflicts of interest in this work.

\section{References}

1. Petersen RC. Mild cognitive impairment. N Engl J Med. 2011;364(23): 2227-2234.
2. Petersen RC, Caracciolo B, Brayne C, Gauthier S, Jelic V, Fratiglioni L. Mild cognitive impairment: a concept in evolution. J Intern Med. 2014; 275(3):214-228.

3. Gordon C, Martin DJ. Mild cognitive impairment. Expert Rev Neurother. 2013;13(11):1247-1261.

4. Teixeira CVL, Gobbi LTB, Corazza DI, Stella F, Costa JLR, Gobbi S. Non-pharmacological interventions on cognitive functions in older people with mild cognitive impairment. Arch Gerontol Geriatr. 2012; 54(1):175-180.

5. Cooper C, Li R, Lyketsos C, Livingston G. Treatment for mild cognitive impairment: systematic review. Br J Psychiatry. 2013;203(3): $255-264$.

6. Horr T, Messinger-Rapport B, Pillai JA. Systematic review of strengths and limitations of randomized controlled trials for non-pharmacological interventions in mild cognitive impairment: focus on Alzheimer's disease. J Nutr Health Aging. 2015;19(2):141-153.

7. Li H, Li J, Li N, Li B, Wang P, Zhou T. Cognitive Intervention for persons with mild cognitive impairment: a meta-analysis. Ageing Res Rev. 2011;10(2):285-296.

8. Reijnders J, Heugten CV, Boxtel MV. Cognitive interventions in healthy older adults and people with cognitive impairment: a systematic review. Ageing Res Rev. 2013;12(1):263-275.

9. Scott J, Spector A. A review of the effectiveness of memory interventions in mild cognitive impairment. Int Psychogeriatr. 2011;23(4): 526-538.

10. Baker LD, Frank LL, Foster-Schubert K, et al. Effects of aerobic exercise on mild cognitive impairment. Arch Neurol. 2010;67(1):71-79.

11. Suzuki T, Shimada H, Makizako H, et al. Effects of multicomponent exercise on cognitive function in older adults with amnestic mild cognitive impairment: a randomized controlled trial. BMC Neurol. 2012; 12(1):128.

12. Hughes TF, Flatt JD, Fu B, Chang CCH, Ganguli M. Engagement in social activities and progression from mild to severe cognitive impairment: the MYHAT study. Int Psychogeriatr. 2013;25(4):587-595.

13. Pitkala KH, Routasalo P, Kautiainen H, Sintonen H, Telvis RS. Effects of socially simulating group intervention on lonely, older people's cognition: a randomized controlled trial. Am J Geriatr Psychiatry. 2011; 19(7):654-663.

14. Buschert VC, Friese U, Teipel SJ, et al. Effects of a newly develop cognitive intervention in amnestic mild cognitive impairment and mild Alzheimer's Disease: a pilot study. J Alzheimers Dis. 2011;25(4): 679-694.

15. Dannhauser TM, Cleverley M, Whitfield TJ, Flectcher B, Stevens T. A complex multimodal activity intervention to reduce the risk of dementia in mild cognitive impairment - ThinkingFit: pilot and feasibility study for a randomized controlled trial. BMC Psychiatry. 2014;14(1):129.

16. Hwang HR, Choi SH, Yoon DH, et al. The effect of cognitive training in patients with mild cognitive impairment and early Alzheimer's Disease: a preliminary study. J Clin Neurol. 2012;8(3):190-197.

17. Hyer L, Scott C, Kyles J, Dhabliwala J, McKenzie L. Memory intervention: the value of a clinical holistic program for older adults with memory impairment. Aging Ment Health. 2014;18(2):169-178.

18. Rapp S, Brenes G, Marsh AP. Memory enhancement training for older with mild cognitive impairment: a preliminary study. Aging Ment Health. 2002;6(1):5-11.

19. Troyer AK, Murphy KJ, Anderson ND, Moscovitch M, Craik FIM. Changing everyday memory behavior in amnestic mild cognitive impairment: a randomized controlled trial. Neuropsychol Rehabil. 2008; 18(1):65-88.

20. Tsolaki M, Kounti F, Agogiatou C, et al. Effectiveness of nonpharmacological approaches in patients with mild cognitive impairment. Neurodegener Dis. 2011;8(3):138-145.

21. Buschert VC, Giegling I, Teipel SJ, et al. Long-term observation of a multicomponent cognitive intervention in mild cognitive impairment. J Clin Psychiatry. 2012;73(12):e1492-e1498.

22. Kwok T, Wong A, Chan G, et al. Effectiveness of cognitive training for Chinese elderly in Hong Kong. Clin Interv Aging. 2013;8:213-219. 
23. Mok E, Lai KY, Wong LF, Wan P. Living with early-stage dementia: the perspective of older Chinese people. J Adv Nurs. 2007;59(6): 591-600.

24. Lam CS, Tsang HWH, Corrigan PW, et al. Chinese lay theory and mental illness stigma: implications for research and practices. J Rehabil. 2010;76(1):35-40.

25. Young KW, Kwok T, Ng P. Single blind randomized control trial on support group for Chinese persons with mild dementia. Clin Interv Aging. 2014;2014(9):2105-2112.

26. Chan CLW. An Eastern Body-Mind-Spirit Approach - A Training Manual with One Second Techniques. 2nd ed. Hong Kong: Hong Kong University; 2006.

27. Leung PY, Chan LW, Ng SM, Lee MY. Towards Body-Mind-Spirit integration: East meets West in clinical social work practice. Clin Soc Work J. 2009;37(4):303-311.

28. Young KW. A randomized control study on psycho-education group on improving health-related quality of life of Chinese persons with major neurocognitive disorder. Clin Gerontol. 2016;39(5):449-467.

29. Ng P, Tsun A, Su S, Young KW. Cognitive behavioural therapy in the Chinese cultural context: a case report. Asia Pac Psychiatry. 2013;5(3): 205-211.

30. Hutchens RL, Kinsella GJ, Ong B, et al. Knowledge and use of memory strategies in amnestic mild cognitive impairment. Psychol Aging. 2012; 27(3):768-777.

31. American Psychiatric Association. Diagnostic and Statistical Manual of Mental Disorders. 5th ed. Washington, DC: American Psychiatric Association; 2013.
32. Yeung PY, Wong LL, Chan CC, Leung JLM, Yung CY. A validation study of the Hong Kong version of Montreal Cognitive Assessment (HK-MoCA) in Chinese older adults in Hong Kong. Hong Kong Med J. 2014;20(6):504-510.

33. Chiu HF, Lee HC, Chung WS, Kwong PK. Reliability and validity of the Cantonese version of mini-mental state examination - a preliminary study. J Hong Kong Coll Psychiatr. 1994;4:25-28.

34. Nasreddine ZS, Phillips NA, Bedirian V, et al. The Montreal Cognitive Assessment, MoCA: a brief screening tool for mild cognitive impairment. J Am Geriatr Soc. 2005;53(4):695-699.

35. Cohen J. Statistical Power Analysis for the Behavioral Sciences. 2nd ed. Hillsdale, NJ: Lawrence Erlbaum Associates; 1988.

36. Belleville $\mathrm{S}$. Cognitive training for persons with mild cognitive impairment. Int Psychogeriatr. 2008;20(1):57-66

37. Faucounau V, Wu YH, Boulay M, De Rotrou J, Rigaud AS. Cognitive intervention programmes on patients affected by mild cognitive impairment: a promising intervention tool for MCI. J Nutr Health Aging. 2010;14(1):31-35.

38. Moro V, Condoleo MR, Sala F, Pernigo S, Moretto G, Gambina G. Cognitive stimulation in a-MCI: an experimental study. Am J Alzheimers Dis Other Demen. 2012;27(2):121-130.

39. Kurz A, Pohl C, Ramsenthaler M, Sorg C. Cognitive rehabilitation in patients with mild cognitive impairment. Int J Geriatr Psychiatry. 2009; 24(2):163-168.

40. Kinsella GJ, Mullaly E, Rand E, et al. Early intervention for mild cognitive impairment: a randomized controlled trial. J Neurol Neurosurg Psychiatry. 2009;80(7):730-736.
Clinical Interventions in Aging

\section{Publish your work in this journal}

Clinical Interventions in Aging is an international, peer-reviewed journal focusing on evidence-based reports on the value or lack thereof of treatments intended to prevent or delay the onset of maladaptive correlates of aging in human beings. This journal is indexed on PubMed Central, MedLine,

\section{Dovepress}

CAS, Scopus and the Elsevier Bibliographic databases. The manuscript management system is completely online and includes a very quick and fair peer-review system, which is all easy to use. Visit http://www.dovepress. com/testimonials.php to read real quotes from published authors. 